\title{
O QUE DIZEM AS NARRATIVAS DE ESTUDANTES DE PEDAGOGIA SOBRE SUA FORMAÇÃO MATEMÁTICA?
}

\section{- JANE MARIA BRAGA}

Universidade Federal de Juiz de Fora

\section{REGINALDO FERNANDO CARNEIRO}

Universidade Federal de Juiz de Fora

RESUMO Uma possibilidade de investigação e formação do professor que ensina matemática, nos anos iniciais do Ensino Fundamental, pode ser efetivada pela escrita de narrativas. Temos como objetivo, neste artigo, investigar as percepções de estudantes de Pedagogia sobre sua formação matemática na Educação Básica e na disciplina Fundamentos Teóricos e Metodológicos da Matemática I - FTM I - a partir de narrativas escritas. Para tanto, desenvolvemos uma pesquisa qualitativa em que utilizamos, para a produção de dados, duas narrativas de 58 estudantes de um curso de Pedagogia. Na primeira delas, eles abordaram as lembranças de matemática e seu ensino durante a sua escolarização e na seguinte, escrita após terem cursado FTM I, eles retomaram a suas lembranças e refletiam sobre o processo formativo vivenciado nessa disciplina. A análise evidenciou que os estudantes trouxeram lembranças da memorização e da repetição para a aprendizagem, no entanto, alguns apresentaram situações vivenciadas e materiais que rompiam com essa maneira de ensinar matemática. As problematizações e as reflexões ocorridas em FTM I dão indícios que os estudantes passaram a ver o ensino de matemática com outro olhar e que poderão ter uma prática docente diferente daquela que vivenciaram em sua trajetória escolar.

Palavras-chave: Narrativas. Formação matemática. Estudantes de Pedagogia.

\section{ABSTRACT WHAT DO THE NARRATIVES OF PEDAGOGY STUDENTS SAY ABOUT THEIR MATHEMATICAL EDUCATION?}

One possibility of teacher research and education that teaches mathematics in the early years of Elementary School is through the writing of narratives. The purpose of this article is to investigate the perceptions of Pedagogy students about their mathematical education in Basic Education and in the discipline Theoretical and Methodological 
Foundations of Mathematics I - FTM I - from written narratives. We developed a qualitative research in which we used for the data production two narratives of 58 students of a Pedagogy course. In the first one, they addressed the memories of mathematics and its teaching during their schooling and the following, written after they had taken FTM I, they resumed their memories and reflected on the formative process experienced in this subject. The analysis showed that students brought memories of memorization and repetition to the learning of mathematics, however, some presented experienced situations and material that broke like this way of teaching mathematics. Problematizations and reflections that occurred in FTM I give indications that the students started to see the teaching of mathematics with another vision and that they could have a teaching practice different from the one that they experienced in their school trajectory.

Keywords: Narratives. Mathematical education. Pedagogy students.

\section{¿QUÉ DICEN LAS NARRATIVAS DE ESTUDIANTES DE EDUCACIÓN PRIMARIA SOBRE SU FORMACIÓN MATEMÁTICA?}

Una posibilidad de investigación y formación del profesor que enseña matemática en la Educación Primaria es a través de la escrita de narrativas. Tenemos como objetivo, en este artículo, investigar las percepciones de estudiantes de Educación Primaria sobre su formación matemática en la Educación Básica y en el curso Fundamentos Teóricos y Metodológicos de la Matemática I - FTM I - por medio de narrativas escritas. Así que desarrollamos una investigación cualitativa en que utilizamos para recogida de datos dos narrativas de 58 estudiantes de un curso de Educación Primaria. En la primera, ellos abordaran los recuerdos de matemática y su enseñanza durante su escolarización y en la siguiente, escrita después de haber hecho FTM I, ellos volvieran a sus recuerdos y reflexionaran sobre el proceso formativo vivido en el curso. El análisis evidenció que los estudiantes se recordaran de la memorización y de la repetición para el aprendizaje de la matemática, sin embargo, algunos presentaran situaciones vividas y materiales que rompieron con esa manera de enseñar la matemática. Las problematizaciones y reflexiones ocurridas en FTM I nos dan indicios de que los estudiantes pasaran a tener una nueva mirada hacía la enseñanza de la matemática y que podrán tener una práctica docente diferente de aquella que vivieran en su trayectoria escolar.

Palabras clave: Narrativas. Formación matemática. Estudiantes de Educación Primaria. 


\section{Introdução}

A formação inicial e continuada de professores que ensinam matemática nos anos iniciais tem sido discutida e debatida, nos últimos anos, em muitas pesquisas e em políticas públicas como, por exemplo, o Pacto Nacional pela Alfabetização na Idade Certa.

Para contribuir com esse debate, neste artigo, temos como objetivo investigar as percepções de estudantes de Pedagogia sobre sua formação matemática na Educação Básica e na disciplina Fundamentos Teóricos e Metodológicos da Matemática I - FTM I - a partir de narrativas escritas.

No curso de Pedagogia investigado, há duas disciplinas que abordam aspectos da matemática, Fundamentos Teóricos e Metodológicos da Matemática I e II - FTM - com carga horária de 60 horas cada uma. Essas disciplinas são oferecidas no quarto e no quinto período do curso, portanto, no segundo semestre de um ano e no primeiro semestre do ano seguinte.

0 professor da disciplina solicita aos estudantes que escrevam narrativas durante as aulas que são utilizadas tanto para a avaliação do seu andamento como também para verificar o movimento dos futuros professores nesse processo formativo.

São escritas, via de regra, de três a quatro narrativas por semestre letivo. Na primeira narrativa da disciplina Fundamentos Teóricos e Metodológicos da Matemática I, os estudantes relatam suas lembranças com relação à matemática e seu ensino enquanto alunos da Educação Básica. Essa narrativa é devolvida para que eles a retomem e escrevam um outro texto narrativo, na segunda disciplina, buscando refletir sobre as lembranças referentes à matemática e ao processo que vivenciaram na primeira disciplina.

Essa dinâmica nos apresenta indícios de que eles começam a ver a matemática com outro olhar e que percebem que podem ensiná-la de uma maneira diferente daquela que aprenderam. Analisamos, neste artigo, essas duas primeiras narrativas, respectivamente, de FTM I e FTM II.

A partir do exposto, trazemos inicialmente o referencial teórico que embasa nossas discussões seguido dos aspectos metodológicos. Depois apresentamos e analisamos os dados que emergiram das narrativas e, por fim, tecemos algumas considerações.

\section{O desenvolvimento profissional de professores que ensinam matemática e as narrativas}

Compreendemos o desenvolvimento profissional de professores na perspectiva de Marcelo e Vaillant (2009), que o consideram com a conotação de evolução e continuidade, superando a simples justaposição entre a formação inicial e continuada. Assim, o desenvolvimento profissional docente caracteriza-se "por uma atitude permanente de indagação, de formulação de perguntas e problemas e a busca de suas soluções" (MARCELO; VAILLANT, 2009, p. 75).

Para esses autores, não é mais possivel pensar que a formação inicial e a experiência prática são suficientes para o trabalho docente. Assim, o desenvolvimento profissional é um processo complexo e multidimensional, que ocorre de forma individual e coletiva e é perpassado por diferentes experiências formativas.

O desenvolvimento profissional é um processo que vai se compondo, não apenas pela agregação de novos conhecimentos, mas também pela (re)significação e a (re)construção dos conhecimentos docentes. É importante que faça parte desse processo a experiência dos professores, em diferentes espaços forma- 
tivos, como em cursos de graduação e de curta duração, em congressos, em palestras, em oficinas, em grupos de estudo, em horários de trabalho coletivo, na escola e na sala de aula.

No desenvolvimento profissional do professor que ensina matemática nos anos iniciais, temos visto que sua formação inicial apresenta muitas lacunas, como destacam Nacarato, Mengali e Passos (2009), pois os futuros professores têm contato com o ensino e a aprendizagem de matemática em disciplinas com carga horária reduzida e não vivenciam os fundamentos da matemática e da prática da pesquisa em educação matemática. Considera-se que a carga horária é reduzida, pois é condensada em poucas disciplinas, às vezes em uma única de 60 horas, uma área de saber que requer construção de conceitos, compreensão de seus fundamentos e estratégias de ensino para a etapa da Educação Infantil e anos iniciais do Ensino Fundamental.

Dessa forma, a prática profissional desses docentes reproduz a dos professores que eles tiveram, em sua escolarização, que têm forte influência na sua identidade e na constituição de seu modelo de aula de matemática, pois tiveram um ensino de matemática pautado nas operações aritméticas e que enfatizou apenas os algoritmos das operações fundamentais (NACARATO; MENGALI; PASSOS, 2009).

Por isso, as práticas vividas na formação inicial são de grande importância para (re) significar e construir conceitos e concepções. Este estudo evidencia o quanto a matemática pode ser "um bicho de sete cabeças", ancorada em práticas de repetição, memorização e sofrimento, e o quanto ela pode ser divertida e com sentido, a partir de vivências no curso de Pedagogia.

Serrazina (2012, p. 268) explicita que o professor precisa "ter oportunidades de viver experiências matemáticas do tipo das que se espera que proporcione aos alunos". Dessa forma, não é possível apenas falar sobre como deve ser o ensino, mas também se deter em práticas que possibilitem a experiência de uma matemática com sentido.

Tardif (2012, p. 103, grifo do autor), ao tratar dos saberes docentes e da formação profissional destaca que:

Os saberes que servem de base para o ensino, isto é, os fundamentos do saber-ensinar, não se reduzem a um 'sistema cognitivo' que, como um computador, processa as informações a partir de um programa anteriormente definido e independente tanto do contexto da ação no qual ele se insere quanto da sua história anterior. $\mathrm{Na}$ realidade, os fundamentos do ensino são, a um só tempo, existenciais, sociais e pragmáticos.

Ao caracterizar os referidos saberes, o autor deixa claro que o saber existencial está vinculado a sua vida, a suas experiências emocionais, afetivas, pessoais e interpessoais, não se restringindo apenas à área acadêmica. 0 docente carrega consigo toda a sua trajetória vivida e busca memórias e esquemas que o ajudem a resolver e organizar novas informações. Nessa perspectiva, "levá-los a contar a história de seu saber-ensinar, através das experiências pessoais e profissionais que foram significativas para eles", contribui para a constituição da identidade profissional (TARDIF, 2012, p. 103).

Também são saberes sociais, porque são oriundos de fontes diversas (família, escola, universidade), documentos oficiais (curriculares, ciências da educação etc.), cabendo ao docente equacionar essas diferentes fontes, legitimando, adaptando, invalidando, reproduzindo um e outro, com maior ou menor intensidade, de acordo com suas concepções e as forças (externas) exercidas no momento de sua atuação, o que estará de acordo com um tempo e um espaço específico.

São saberes pragmáticos porque estão “ligados tanto ao trabalho quanto à pessoa do trabalhador", portanto, são saberes sobre a 
função do professor e suas condições de desenvolvimento. "Sua utilização depende de sua adequação às funções, aos problemas educacionais e às situações do trabalho, assim como os objetivos educacionais que possuem um valor social" (TARDIF, 2012, p. 105). São ainda saberes mobilizados nas interações com os outros sujeitos envolvidos no processo educacional, em relações mais ou menos diretas, que abrangem afetividade, normatividade, interpretações e reações diante das situações vividas.

Nesse contexto, uma possibilidade de trabalho, na formação inicial de professores que ensinam matemática, são as narrativas, que permitem levá-los a refletir sobre sua formação matemática experienciada na Educação Básica e também nesse processo formativo. Assim, nas disciplinas de Fundamentos Teóricos e Metodológicos da Matemática I e II de um curso de Pedagogia, os estudantes são solicitados a escrever narrativas.

Nas narrativas, podemos observar como esses saberes se relacionam, coexistem e favorecem concepções sobre o ensino de matemática. Acioná-los, desenvolvê-los e ampliá -los é o objetivo do exercício escrito, servindo de base para este estudo.

A narrativa é também entendida como metodologia de pesquisa em Educação, uma vez que quando "saem dos muros da escola e passam a ser vistos como enunciados úteis para compor os dados de pesquisa do campo educacional, acontece uma valorização desse gênero e de seus produtores" (SERODIO; PRADO, 2015, p. 91).

Ainda para Serodio e Prado (2015, p. 91), "aos poucos, ao passar do gênero oral para o escrito, essas narrativas se tornam textos acadêmicos, além de configurarem-se como um modo de produzir o conhecimento (científiconarrativo)".

Ao realizarem o registro escrito, os estudantes de Pedagogia fizeram um exercício de estudante-pesquisador-narrador, sendo possivel analisar suas memórias e identificar diferentes saberes, concepções e aspirações. Esse movimento favorece a constituição do ser docente. Quando confrontam suas primeiras memórias com o segundo exercício, realizado após cursar FMT I, indicam (re)significações do ensino de matemática.

Espera-se assim um saber-fazer que atenda as demandas atuais da educação: garantir os direitos de aprendizagem, favorecendo não só a permanência da criança na escola, mas sua qualidade, seu sucesso, com um ensino de matemática que tenha a ver com seu cotidiano, e que também favoreça o raciocínio lógico, estabelecendo relações entre os diferentes eixos da matemática, entre as diferentes áreas do conhecimento, entre a escola e a vida.

Outra demanda crescente é desenvolver uma formação docente em que o professor seja sujeito de sua ação - problematize, reflita e teorize -, promovendo a construção contínua de conhecimentos, e podendo redimensionar suas práticas frente aos desafios da sala de aula.

\section{Caminhos da pesquisa}

A partir do objetivo da pesquisa, investigar as percepções de estudantes de Pedagogia sobre sua formação matemática em narrativas escritas, desenvolvemos uma pesquisa qualitativa (BOGDAN; BIKLEN, 1994) em que buscamos apreender nas narrativas as percepções dos futuros professores sobre seu desenvolvimento profissional.

0 professor, ao recorrer à memória como ferramenta de aprendizagem e formação, percorre o caminho de abertura e disponibilidade para novas indagações e descobertas, cria projetos, revê, abandona e valoriza práticas já percorridas e ilumina esse processo com as lembranças remexidas na gaveta dos guardados. (PLACCO; SOUZA, 2006, p. 39) 
A opção por esse exercício narrativo revela possibilidades de compreensão de práticas em tempos e espaços distintos, contribuindo para o desenvolvimento profissional do ser docente. Revisitar práticas enquanto discentes gera novos sentidos e apropriações do fazer pedagógico, o que é possibilitado pelo processo de ação-reflexão-ação. Quando os estudantes de Pedagogia se tornam sujeitos de seu processo de conheci- mento, com base nas memórias narradas/ ouvidas no grupo, passam a ser produtores de saberes, relacionando os pressupostos teóricos com as práticas vividas (e lembradas) no cotidiano escolar e referendados pelos textos estudados.

Neste artigo, foram analisadas as narrativas de 58 estudantes do curso de Pedagogia de três turmas diferentes, como podemos ver no Quadro 1:

Quadro 1 - Turmas e número de alunos

\begin{tabular}{|c|c|}
\hline Ano & Número de alunos \\
\hline $2015 / 2016$ & 24 \\
\hline $2016 / 2017$ & 12 \\
\hline $2017 / 2018$ & 22 \\
\hline Total & 58 \\
\hline
\end{tabular}

Fonte: Elaboração dos autores.

Nas três turmas em análise, o número de estudantes era maior do que a quantidade de narrativas indicadas no quadro, mas alguns deles não deram continuidade à disciplina, no semestre seguinte, por isso, optamos apenas pelas narrativas daqueles que fizeram os dois registros, ou seja, que escreveram sobre suas lembranças com relação à matemática e seu ensino, enquanto estudantes, e a segunda escrita, em que retomaram a primeira e refletiram sobre o processo vivenciado durante a disciplina de Fundamentos Teóricos e Metodológicos II.

Para identificação das narrativas fizemos a opção pela(s) letra(s) inicial(is) do nome do estudante e trazemos ao final do excerto $\mathrm{NI}$ ou NII a indicação referente à primeira ou à segunda narrativa respectivamente, assim como o ano dos registros.

Nesta investigação, a escrita de narrativas buscou promover reflexões e problematizações sobre a formação dos futuros professores que ensinarão matemática nos anos iniciais e também para a produção dos dados em estu- do. Compreendemos, como Cunha (1997, p. 3), que a utilização de narrativas na pesquisa e no ensino permite a "desconstrução/construção das próprias experiências tanto do professor/ pesquisador como dos sujeitos da pesquisa e/ ou do ensino". Assim, a escrita narrativa pode tornar-se um processo emancipatório em que se aprende ao construir seu próprio desenvolvimento profissional.

Ainda de acordo com Cunha (1997, p. 7), as pesquisas com narrativas são ao mesmo tempo investigação e formação, pois há uma relação dialética entre a teoria e a realidade. "Ao mesmo tempo em que a realidade informa a teoria esta, por sua vez, a antecede e permite percebê -la, reformulá-la, dar conta dela, num processo sem fim de distanciamento e aproximação".

No tratamento dos dados, utilizamos a análise de conteúdo que, para Bardin (1977, p. 44), é um conjunto de técnicas que busca “obter por procedimentos sistemáticos e objectivos de descrição do conteúdo das mensagens indicadores (quantitativos ou não) que permi- 
tam a inferência de conhecimentos relativos às condições de produção/recepção (variáveis inferidas) destas mensagens".

Escolhemos a análise de conteúdo temática que permite, a partir de um conjunto de dados brutos, organizar de forma sistemática as informações, interpretá-las e processá-las, para chegar-se a alguns resultados - buscamos regularidades, determinamos suas partes, aspectos que consideramos mais importantes, extraímos elementos comuns e divergentes (BOLÍVAR, [201-]).

A análise temática pode ser utilizada para investigar motivações, opiniões, crenças, concepções, atitudes, valores, tendências, entre outros aspectos que podem ser encontrados nas narrativas e também porque percebemos muitas aproximações em relação a diferentes temas que fizeram emergir os eixos de análise

Emergiram três eixos de análise - percepções dos estudantes sobre a matemática, recursos didáticos no ensino de matemática e o professor de matemática da Educação Básica - que passaremos a apresentar a seguir.

\section{Olhares possiveis}

Placco e Souza (2006, p. 32), ao estudarem os processos de aprendizagem do adulto professor, destacam a memória como um de seus fundamentos essenciais, pois o "ato de evocar, remexe os conteúdos da memória e nesse processo interno pode acolher seus próprios significados e os dos outros que relatam e compartilham". A experiência de refletir sobre a memória e reconstruí-la, individual e coletivamente, pode provocar transformações nos modos de perceber e construir novos conceitos; por essa potencialidade, fizemos a opção pelo uso das duas narrativas das disciplinas Fundamentos Teórico e Metodológicos em Matemática I e II, para desenvolver o estudo sobre a matemática nos anos iniciais do Ensino Fundamental, bem como organizar o processo de formação inicial do professor, de forma mais efetiva.

A narrativa I teve por objetivo evocar lembranças, enquanto discente, na trajetória escolar dos futuros professores, destacando a disciplina matemática, e a narrativa II buscou refletir sobre a narrativa I e suas vivências, tendo em vista a construção de uma futura prática docente. Na perspectiva de Placco e Souza (2006, p. 37):

Percorrer o passado da escola e da sala de aula
e seus rituais nos permite descortinar a histó-
ria de nossa escola e de nossa profissão, que
deve ser analisada, refletida e partilhada com
as novas gerações de educadores. Que essa
abordagem de memória gere na formação dos
educadores caminhos transformadores para a
escola brasileira do presente.

As autoras ainda afirmam "que a memória é matéria-prima para a possibilidade da transformação" (2006, p. 35), tanto do professor que propõe esse exercício como dos estudantes que o fazem, pois possibilita movimentos, que desencadeiam sentimentos, inquietações, iniciativas, proposições a partir do vivido, refletido e significado, por meio da experiência, não somente com a matemática, mas com todo o conhecimento construído ao longo dos diferentes contextos escolares.

As narrativas dos estudantes de Pedagogia construídas nas referidas disciplinas evidenciam valores, práticas, recursos, impasses, potencialidades e limites do cotidiano escolar, sendo possivel retomar conteúdos e estratégias do ensino de matemática a serem abordados na formação docente.

Os Quadros 2 e 3 trazem alguns recortes dos aspectos da prática pedagógica que apareceram nas narrativas I e II, evidenciando as reflexões que se seguem. Esse exercício de copilar os dados permite refletir sobre alguns agrupamentos que são evidenciados com maior ou menor intensidade. 
Quadro 2 - Aspectos da prática pedagógica lembrados anterior a disciplina Fundamentos Teóricos e Metodológicos da Matemática I

\begin{tabular}{|c|c|c|c|c|}
\hline \multirow[b]{2}{*}{ Narrativa I } & \multicolumn{4}{|c|}{ Quantidade/ano } \\
\hline & $2015 / 2016$ & $2016 / 2017$ & $2017 / 2018$ & Total \\
\hline Decoreba sem entender & 4 & 5 & 5 & 14 \\
\hline Abstrato, sem sentido & 3 & 0 & 1 & 4 \\
\hline Relação de medo/ódio com a matemática & 2 & 3 & 4 & 9 \\
\hline Dificuldade com a tabuada & 12 & 2 & 4 & 18 \\
\hline Preso a livro didático, quadro e caderno & 3 & 7 & 5 & 15 \\
\hline Repetição para gravar conteúdo & 3 & 2 & 6 & 11 \\
\hline Dificuldade na fração & 1 & 0 & 0 & 1 \\
\hline $\begin{array}{l}\text { Professor como motivador, marcaram minha } \\
\text { vida }\end{array}$ & 6 & 6 & 12 & 24 \\
\hline Professor como carrasco & 3 & 2 & 13 & 18 \\
\hline Aulas expositivas e conteudistas & 3 & 1 & 2 & 6 \\
\hline Presença de jogos e brincadeiras & 4 & 2 & 0 & 6 \\
\hline Presença do material dourado & 2 & 0 & 4 & 6 \\
\hline $\begin{array}{l}\text { Trabalho prático: idas a supermercados, } \\
\text { divisão de bolo/pizza para aprender fração }\end{array}$ & 2 & 0 & 3 & 5 \\
\hline Feira de Matemática & 1 & 0 & 0 & 1 \\
\hline $\begin{array}{l}\text { Dificuldade nos anos finais do Ensino } \\
\text { Fundamental e Médio }\end{array}$ & 8 & 7 & 12 & 27 \\
\hline $\begin{array}{l}\text { Experiências boas até os anos iniciais do } \\
\text { Ensino Fundamental }\end{array}$ & 4 & 3 & 4 & 11 \\
\hline Matéria que mais apresentou dificuldades & 2 & 2 & 2 & 6 \\
\hline Matéria que tinha facilidade & 1 & 0 & 5 & 6 \\
\hline Nota baixa em matemática e recuperação & 6 & 5 & 7 & 18 \\
\hline $\begin{array}{l}\text { Avaliação: repetição, lista de exercícios, sem } \\
\text { sentido }\end{array}$ & 7 & 4 & 4 & 15 \\
\hline Greve (sem reposição, prejuízos) & 0 & 0 & 2 & 2 \\
\hline Não lembra muito & 3 & 2 & 6 & 11 \\
\hline
\end{tabular}

Fonte: Elaboração dos autores.

Podemos observar vários aspectos que evidenciam como a matemática era ensinada, por exemplo, a partir da memorização e da reprodução de conteúdos, o que causava dificuldades e fazia surgir sentimentos negativos com relação à disciplina. As aulas eram, via de regra, expositivas, e o professor se limitava ao livro didático.
Além disso, alguns futuros professores tiveram contato, enquanto estudantes, com uma forma diferente de aprender matemática, em que seus professores utilizaram jogos e materiais manipuláveis e práticas de sala de aula que rompiam com o modelo das aulas expositivas.

Podemos também verificar que o professor é apresentado, nas narrativas, tanto por as- 
pectos positivos quanto negativos, no que se refere à maneira como interagia com os alunos, e não pela maneira como abordava os conteúdos matemáticos em suas aulas.

O professor pode ter a intenção de ensinar os conceitos e conteúdos de sua disciplina, mas a sua fala, seus gestos, suas atitudes, seus valores, que emergem na aula, mesmo de forma inconsciente, são aprendizagens mais significativas e permanentes para os alunos (MORALES, 1999).

No decorrer de uma mesma narrativa, observamos vários aspectos, que foram quanti- ficados pela proximidade de significados, de acordo com que aparece nos registros. Muitos destacam aspectos positivos, nos anos iniciais, e negativos, nos anos finais do Ensino Fundamental e Ensino Médio.

As práticas vivenciadas pelos estudantes formam o núcleo da cultura escolar que são os “modos de atuar que, sedimentados ao longo do tempo, são adotados e interiorizados de um modo automático, não reflexivo, pelos professores e alunos" (VIÑAO FRAGO, 1998, p. 179). Assim, constituem as representações de matemática que influenciam a maneira como irão atuar.

Quadro 3 - Aspectos da prática pedagógica indicados após cursarem a disciplina Fundamentos Teóricos e Metodológicos da Matemática I

\begin{tabular}{|c|c|c|c|c|}
\hline \multirow[t]{2}{*}{ Narrativa II } & \multicolumn{4}{|c|}{ Quantidade } \\
\hline & $2015 / 2016$ & $2016 / 2017$ & $2017 / 2018$ & Total \\
\hline Matemática mais prazerosa sem decoreba & 8 & 3 & 5 & 16 \\
\hline Aulas mais dinâmicas do que teve & 2 & 1 & 3 & 6 \\
\hline $\begin{array}{l}\text { Matemática na prática melhor do que situação } \\
\text { imaginária/abstrata }\end{array}$ & 1 & 0 & 0 & 1 \\
\hline Matemática não é complicada, sem medos & 1 & 3 & 4 & 8 \\
\hline Como ensinar a Matemática é a questão & 5 & 1 & 4 & 10 \\
\hline $\begin{array}{l}\text { Uso de diferentes recursos: jogos, brincadeiras, } \\
\text { músicas e material manipulável }\end{array}$ & 12 & 9 & 9 & 30 \\
\hline Mudança na forma como viam a matemática & 7 & 2 & 6 & 15 \\
\hline $\begin{array}{l}\text { A iniciativa do professor pode fazer o } \\
\text { diferencial }\end{array}$ & 7 & 2 & 6 & 15 \\
\hline Respeito os processos de solução dos alunos & 2 & 0 & 1 & 3 \\
\hline $\begin{array}{l}\text { Análise e aprendizagem com as crianças e suas } \\
\text { estratégias }\end{array}$ & 4 & 1 & 1 & 6 \\
\hline Uso do lúdico & 14 & 2 & 6 & 22 \\
\hline Ampliação do que conhecia de matemática & 1 & 2 & 8 & 11 \\
\hline $\begin{array}{l}\text { Oportunidade de relacionar o conteúdo com o } \\
\text { mundo a sua volta }\end{array}$ & 1 & 2 & 3 & 6 \\
\hline $\begin{array}{l}\text { Matemática com a literatura infantil: } \\
\text { potencialidade }\end{array}$ & 3 & 1 & 2 & 6 \\
\hline Boas práticas por meio da experimentação & 1 & 0 & 3 & 4 \\
\hline Trabalho interdisciplinar & 0 & 1 & 5 & 6 \\
\hline
\end{tabular}

Fonte: Elaboração dos autores. 
A partir da experiência com a disciplina FTM I, os futuros professores evidenciam indícios de que esse processo fez com que eles começassem a lançar um outro olhar para a matemática, e que poderiam ser professores diferentes dos que tiveram em sua vida escolar. Assim, explicitam que a matemática não precisa ser monótona, mas prazerosa, e que seu ensino pode se fazer por meio de jogos, brincadeiras, materiais manipuláveis, literatura infantil etc. Ainda afirmam que podem relacionar os conceitos e conteúdos matemáticos a aspectos práticos da vida dos alunos e realizar um trabalho interdisciplinar, referindo-se a uma proposta em que os docentes das disciplinas de FTM e de Ciências trabalharam juntos, a partir de temas escolhidos pelos estudantes.

Em seguida, apresentamos e discutimos os dados presentes nas narrativas escritas dos estudantes, para o fazer matemático, demostrando o potencial da memória/narrativa no processo de formação.

\section{Percepções dos estudantes sobre a matemática}

Há um número significativo de narrativas que apontam para uma matemática escolar sem significado, pautada na repetição, na memorização, no livro didático, sem sentido, fora e dentro da escola. Com a vivência da disciplina de FTM I, no curso de Pedagogia, os estudantes mostram indícios de que novos olhares foram construídos, a partir de leituras, reflexões e práticas possibilitadas nessa disciplina. Alguns trechos descrevem essa construção:

D - Não vejo a Matemática agora como uma dificuldade a ser vencida, mas como uma ferramenta utilizada em todos os momentos e que está profundamente relacionada com a vida $e$ a realidade do mundo. E também no decorrer deste curso compreendi que há formas e modos diferenciados para se ensinar matemática, $e$ que cabe ao professor mostrar sensibilidade $e$ comprometimento na execução deste trabalho para que seja realmente produtivo e significativo para o aluno. (NII - 2015/2016)

$R$ - Existem diferentes "maneiras" de ensinar matemática, tem que ser de um jeito que atraia a turma toda. $O$ ensino de matemática ligado a literatura infantil. (NII - 2015/2016)

$\pi$ - O que mudou minha visão em relação a matemática é que ela (a Matemática) não tem culpa... que ela pode ser muito mais interessante $e$ atraente para os alunos dependendo da estratégia e forma de ensinar. (NII - 2017/2018)

LA - A principal diferença que percebo ao relembrar como foi a disciplina de Matemática quando eu estava na escola e como foi trabalhada em Fundamentos da Matemática I é a interdisciplinaridade. Na escola não havia essa relação, ou não era percebida por nós, alunos, e ressaltada pelos professores como ocorreu na graduação. Perceber como isso é possivel acontecer na prática e em como pode enriquecer para os alunos e também para os professores. (NII - 2017/2018).

E - Minha visão e sentimentos sobre a Matemática sofreram bastante mudanças no semestre passado, pois nas primeiras aulas já foi derrubada uma barreira que parecia muito sólida no meu entendimento, já que na infância e adolescência a matemática me foi apresentada de maneira complicada, chata e tão dificil que passei a acreditar que apenas quem tinha um "dom especial" poderia lidar com o tanto de problemas, fórmulas, símbolos, sinais etc. (NII - 2017/2018)

Além de indicarem a mudança na maneira como veem a matemática, ao se colocarem como professores, no ensino de matemática, propõem uma prática que tenha sentido para o aluno. Para isso, apontam que é importante considerar o modo de ensiná-la. Os estudantes parecem corroborar os pressupostos de Serrazina (2012, p. 267-268) de que o professor precisa:

Ter oportunidades de viver experiências matemáticas do tipo das que se espera que proporcione aos alunos, pois só assim poderá cumprir uma das suas funções como professor de Ma- 
temática. Desta ideia resulta que, na formação de professores não basta pensar no que deve ser ensinado, é necessário também equacionar o como ensinar.

Ainda segundo a autora, para desempenhar a função de professor, é necessário que sua formação seja pensada levando em consideração o que será ensinado e também o modo como se ensina. Acrescenta ainda que "vários autores reconhecem que os professores têm, eles próprios de viver experiências matemáticas ricas, do tipo das que se espera que proporcionem aos seus alunos e que para eles constituam um desafio intelectual" (SERRAZINA, 2012, p. 272).

Esses aspectos são importantes, pois o futuro professor passa muitos anos na escola e tende a reproduzir práticas daqueles que considera bons professores. Aprende-se muito com a observarção dessas práticas, mas, como alunos, têm acesso somente a uma parte do ensino e aprendizagem, que é a ação em sala de aula e, dessa forma, não conseguem apreender como o professor seleciona os conteúdos que serão ensinados, as estratégias metodológicas para isso etc. (HAMMERNESS et al, 2005).

A experiência na disciplina foi destacada pelos estudantes de Pedagogia como importante estratégia para descontruir ou reforçar como percebiam o ensino de matemática.

S - O mais legal não foi somente saber que existem jogos ou formas diferentes de se trabalhar o conteúdo. Mas sim a vivência de jogos, brincar mesmo, e fazer os exercícios. Então mesmo não tendo vivido na escola "essa" matemática, pude viver na universidade. E como futura professora viver isso é muito importante porque na minha opinião, somente assim poderei possibilitar que as crianças também tenham essa vivência e possam construir relação prazerosa com a matemática. (NII - 2016/2017)

$L Y$ - Gostaria de ressaltar que estou gostando muito das aulas, principalmente, das práticas que através da experimentação podemos vivenciar experiencias únicas que levarei para os meus futuros alunos. (NII - 2015/2016)

$Y-[. .$.$] as duas atividades propostas (trabalho$ com Geometria - Tangran e montagem de figura a partir de três formas geométricas do livro As três partes) nos mostra que é possivel encontrar outros caminhos que chamem a atenção $e$ o interesse dos estudantes, fugindo do "padrão" das escolas que focam no aprendizado através dos livros e do caderno a partir da cópia do conteúdo. (NII - 2017/2018)

$A C$ - Aprendi também a valorizar e respeitar os processos de solução que o aluno pode chegar, por mais que não siga o "roteiro", "caminho" estipulado pelo professor em um problema $e$ também a analisar e aprender com as crianças as suas estratégias nos jogos, por exemplo. (NII - 2015/2016)

$T$ - A disciplina de Fundamentos trouxe uma nova perspectiva de ensino, onde não vejo mais a Matemática como algo maçante e que já me dava desespero ao pensar que chegaria o momento em que teria que ensinar algo que não me agradava. Mas atualmente tenho uma visão de algo fundamental e divertida. (NII - 2015/2016)

$A P$ - [...] percebo em minha vida escolar obtive um bom ensino de matemática, que sempre utilizou o lúdico como ferramenta de ensino. Penso que a partir de minha vida escolar e também da disciplina já concluída obtive um olhar diferente para esse ensino que é mau, tido por muitos da sociedade. (NII - 2015/2016)

J- Hoje penso que tenho o compromisso de ensinar matemática evitando cometer os mesmos erros que me fizeram ter uma visão tão negativa dessa disciplina. É certo que nem sempre vou acertar, no entanto, um ensino de qualidade é um direito de toda criança e o dever de todo professor. (NII - 2015/2016)

Esses excertos evidenciam diversos aspectos sobre a matemática que são importantes para o futuro professor dos anos iniciais. Essas discussões foram possibilitadas pela escrita das narrativas, que permitiram aos estudantes deslocarem-se e refletirem sobre a própria 
prática discente, gerando desenvolvimento profissional. Segundo Passos (2018, p. 183-184):

Narrar a respeito de sua trajetória de formação faz com que professores revelem aprendizagens e também determinadas atuações didáticas que lhe são marcantes. Esse processo de reflexão pedagógica lhes permite compreender as consequências de sua atuação, criar novas estratégias de ensino; revela-nos indícios de seu desenvolvimento profissional. Os textos narrativos possibilitam identificar; compreender e analisar como se dá o processo de produção de conhecimento ainda na formação inicial. Quando uma pessoa produz narrativa ela pode destacar situações positivas ou negativas e reforçar influencias que têm muito significados.

Nas narrativas em estudo, podemos observar diferentes práticas vividas, enquanto discentes, descritas no Quadro 2, que evidenciam situações como: decorar tabuada, exercícios repetitivos, ensino abstrato sem sentido, uso excessivo de livro didático, ausência de situações práticas e prazerosas, professor como carrasco, entre outras. Essas situações foram problematizadas, repensadas durante a disciplina de FTM I, possibilitando um outro entendimento do saber-fazer matemática.

Nos excertos acima, os estudantes demonstraram que podem ser professores diferentes daqueles que tiveram durante sua escolarização, não ficando "presos" somente à utilização do livro didático e de lousa e giz. Um dos motivos foi a disciplina ter proporcionado o contato deles com diferentes jogos, brincadeiras, livros de histórias infantis e materiais manipuláveis.

Os estudantes de Pedagogia explicitaram que é fundamental vivenciar a utilização desses materiais, como apontado por $\mathrm{S}$, ao referirse aos jogos. 0 estudo teórico dos conteúdos, dos conceitos matemáticos e das estratégias de ensino são importantes e foram abordados na disciplina. Contudo, eles também puderam experimentar na prática esses materiais.
Essa manipulação dos materiais e sua experimentação são discutidos por Serrazina e Matos (1996, p. 4), destacam que "um uso inadequado ou pouco exploratório de qualquer material manipulável, pouco ou nada contribuirá para a aprendizagem matemática", pois é necessário perceber e explorar suas características, formular e resolver problemas, favorecer relações e conceitos. Dessa forma, não basta apenas disponibilizar os materiais, sua eficácia estará na maneira de utilizá-lo.

Outro fator destacado pelos estudantes é aprender a valorizar as diferentes formas de resolver um problema, o que mostra a concepção de que a matemática não é algo pronto e acabado, mas que as crianças podem ter suas próprias maneiras de pensar para chegar à sua solução.

Observamos também que alguns futuros professores já tiveram, em sua vida escolar, um contato com uma matemática diferente daquela em que é preciso somente memorizar e repetir procedimentos e fórmulas e que, segundo eles, foi ampliada pela disciplina.

É possivel identificar esses aspectos nas narrativas dos estudantes, principalmente no semestre da disciplina FTM II, pois partem da própria história para refletir sobre o seu futuro fazer profissional, indicando que por meio de sua experiência poderão fazer escolhas mais adequadas como observamos na estudante AC:

$A C$ - Hoje, entendo muitas frustações e dificuldades que passei quando era aluna e acredito que a maioria delas poderia ser evitada se eu tivesse a ajuda e o apoio de meus professores. Por esse motivo, penso que posso acabar auxiliando meus futuros alunos nas frustações deles, para que não criem traumas ou decepções com essa disciplina (matemática) que, além de ter várias coisas interessantes a nos oferecer, nos cerca em quase todos os momentos do cotidiano. (NII - 2016/2017)

Outra estudante, a CA, mostra uma mudança de percepção, entre sua vivência como es- 
tudante na Educação Básica e no Ensino Superior, destacando que é possível, por meio de conhecimento mais específico, ter uma prática diferente do que vivenciou, e apontando as possibilidades para esse desenvolvimento profissional.

CA - Diante de tudo que estudei a minha forma de pensar teve sim uma mudança para melhor, posso não amar a matemática, mas aprendi que podemos inovar com ela. A partir dos jogos, das aulas surpreendentes, das brincadeiras e das dinâmicas, a matemática passou a ter outro conceito em minha concepção. (NII - 2016/2017)

Ambos os trechos das narrativas indicam que as estudantes conseguem reconhecer as dificuldades que enfrentaram com a matemática e que podem fazer com que seus futuros alunos, mesmo que não gostem muito de matemática, não desenvolvam sentimentos negativos em relação à disciplina.

A escrita de narrativas, segundo Josso (2010, p. 71), faz com que seus autores reflitam sobre o que pensam e porque têm aquelas ideias, permitindo a "tomada de consciência de significados novos e enriquecedores para a compreensão de si próprios ou do ambiente que os rodeia", processo reflexivo que pode influenciar a prática de sala de aula desses futuros professores.

Mobilizar a memória de sua trajetória escolar e registrá-la em forma de narrativa escrita revela as marcas, ou seja, os saberes docentes praticados e forjados na história de cada um desses estudantes. Esperamos, portanto, que, ao recorrer à memória sobre sua aprendizagem, isso possa ajudar "a depurar o vivido e decidir como pretende dar continuidade a sua história" (PLACCO; SOUZA, 2006, p. 37). Esse movimento é evidenciado no trecho acima em que a estudante CA indica as possibilidades de uma atuação futura, tendo em vista uma experiência nada agradável com a matemática na Educação Básica, mas que foi (re)significada na formação inicial. Fortalece-se aqui a narrativa como possibilidade metodológica de pesquisa em Educação, pois é possivel tornar-se estudante-pesquisador-narrador. Uma vez que provoca a reflexão, a problematização leva a uma ação mais consciente.

\section{Recursos didáticos no ensino de matemática}

De forma geral, os estudantes remetem à dificuldade presente na área da matemática, ao processo de abstração, de memorização e de repetição. As memórias positivas estão relacionadas ao uso de algum recurso que auxilie na compreensão dos conceitos. São lembrados com mais frequência o material dourado, o bolo para o ensino da fração, a música e o desenho, como estratégias de ensino para aproximar o aluno da matéria pretendida.

M - A matemática entrou bem cedo na minha vida. Tenho vagas lembranças de estar em sala na pré-escola trabalhando com material dourado. (NI - 2015/2016)

LG - Durante os anos iniciais do Ensino Fundamental, me recordo das aulas com o material dourado, que eram divertidas, pois saíamos da rotina de resolver questões no caderno de forma repetitiva e mecânica. Essas questões eram diversos problemas ou operações, normalmente constavam de questões " $a$ " até " $f$ " no mínimo. As turmas gastavam muito tempo copiando as questões e sempre tinha tarefas para casa. (NI -2017/2018)

MP - Me lembro apenas de duas vezes que gostei muito de matemática uma foi quando na 3a série aprendi a mexer com material dourado e fechei uma prova. Outra experiência foi na 6 a série [que] tive um grande professor que ensinava matéria de um jeito muito divertido cantando músicas, fazendo desenhos, isso me fez um dia pensar em ser professora de matemática. $(\mathrm{NI}-2015 / 2016)$

$F$ - As atividades com o ábaco, o material dourado, os jogos (nunca dez, torre de Hanói, o bo- 
liche entre outros) ajudaram a criar um clima de descontração sem perder o foco. Os textos como o livro "Os números" (Georg Ifrah) possibilitaram um aprendizado "suave" com aprofundamentos teóricos de alta qualidade, além dos textos de Romanatto e outros que abordaram questões práticas e cotidianas da sala de aula. (NI- 2015/2016)

$T$ - Uma lembrança muito forte para mim foi aprender fração, já na 4a série, com a professora Maria do Rosário, Dona Rô. Ela levou um bolo para fracionar e como uma aluna de escola pública, qualquer comida diferente na merenda da escola era considerado uma festa. (NI 2015/2016)

AC - [...] fomos a um supermercado com a turma da escola e me recordo que foi minha primeira experiência de comprar sozinha. Lembro que a professora levava vários folhetos e propagandas e fazíamos varias tarefas. (NI - 2015/2016)

Nos relatos, os estudantes apresentam situações vivenciadas, tanto na sua trajetória escolar como na formação inicial, que relacionam ao gosto pela matemática e à utilização de materiais, jogos, músicas etc. Contudo, também destacaram a importância de discussões teóricas, que enriqueceram o processo de sua formação.

Essas afirmações evidenciam a contraposição que os futuros professores fazem à maneira como a matemática muitas vezes é abordada pelos professores, sem justificativa e baseada apenas na reprodução. As ideias e experiências que tiveram durante todo o seu processo formativo podem impactar sua futura prática de sala de aula.

Reforçam também a importância dos recursos manipuláveis para o ensino de matemática.

AP - quando fui para a 1a série do Fundamental [...] me recordo que este colégio sempre utilizava jogos para o ensino de matemática, o que tornava o aprendizado muito mais significativo, prazeroso e divertido. [...] Toda a semana havia um horário destinado para ir na oficina de ma- temática que possuía muitos jogos legais, lembro que eu gostava mais do jogo "Mancala". (NI -2015/2016)

LU - [...] só me lembro de uma atividade que juntamos caixas de ovos e macarrão colorido para montar um ábaco. (NI - 2016/2017)

CT - [...] a professora percebendo a dificuldade dos alunos elaborou aulas nas quais elaboramos figuras geométricas através de dobraduras, o que facilitou a compreensão. Tanto essas aulas, como a professora marcaram o meu aprendizado de Matemática, pelo fato da busca de alternativas para facilitar a compreensão (NI - 2017/2018)

Verificamos que os jogos e materiais manipuláveis marcam positivamente o ensino de matemática, na Educação Básica, e são relacionados, nas narrativas, a uma maneira diferente e divertida de aprender matemática, assim como a uma forma que o professor tinha para buscar minimizar as dificuldades apresentadas pelos alunos.

A tabuada é apontada como um recurso necessário às avaliações e também relacionada ao processo de decorar que gerava sofrimento:

$T$ - Um dos problemas que sempre enfrentei na área foi com a tabuada, demorava muito tempo para decorar e sempre esquecia dias depois da prova. Não importava quantas vezes eu estudasse. (NI-2015/2016)

MF-Recordo-me que possuía muita dificuldade em decorar a tabuada [...] durante o meu Ensino Fundamental fui forçada a decorar a tabuada e várias vezes fui reprimida pela professora por não conseguir decorá-la. (NI-2015/2016)

MN - Nas séries iniciais com o ensino dos números de 0-99 e a tabuada, lembro-me de passar minhas tardes decorando, repetindo, repetindo até saber decor. $(\mathrm{NI}-2017 / 2018)$

GC - Outro fato que me marcou muito foi a arguição da tabuada, que além de criar pânico também induzia a competição entre meninos e meninas (a professora separava em duas filas: meninos e meninas para tomar a tabuada). (NII $-2017 / 2018)$ 
As questões que envolvem a tabuada explicitam perspectiva do professor que se fundamenta no paradigma tecnicista (FIORENTINI, 1995), pelo qual se enfatiza a reprodução, a memorização de fórmulas e algoritmos, em que as aulas ocorrem a partir da exposição dos conteúdos pelo professor.

A memorização da tabuada foi discutida em sala de aula, na disciplina de FTM I, buscando fazer com que os estudantes refletissem sobre suas lembranças e também sobre as possibilidades de trabalhar com esse recurso, em sala de aula, sem a necessidade de decorar.

Com a disciplina cursada, os estudantes de Pedagogia, em sua maioria, como se pode observar no quadro 2, apontam, na segunda narrativa, a importância de recursos didáticos diversificados na construção dos conceitos matemáticos e dos materiais manipuláveis, para sair do "padrão" de repetição sem sentido, apontado na primeira narrativa.

E - As aulas do semestre passado, além de quebrar esse meu preconceito matemático, também serviram como material para eu reconstruir um novo conceito. Aprendi, ao longo do semestre, que através da simplicidade em utilizar materiais acessiveis: caixas, palitos, barbante, o próprio corpo, muita criatividade e boa vontade, é possivel trabalhar conteúdos que parecem complicados como por exemplo: geometria, frações, equações... [...] Outra estratégia muito interessante que aprendi é elaborar uma lista com os interesses dos alunos por assuntos diversos que podem servir como ponto de partida para aulas mais práticas e participativas. (NII - 2017/2018)

LM - Outra coisa que gostei bastante e vou levar para a sala de aula, caso eu opte por trabalhar nessa área, é a construção de sólidos geométricos com jujuba. Foi uma aula bem legal que trabalha o raciocínio de forma lúdica e divertida. (NII - 2017/2018)

Novamente, os materiais utilizados nas aulas de FTM I foram motivadores para os estudantes, que os indicam como possibilidades de utilização, em sua prática futura, nos anos iniciais, apresentando-os como contribuições da disciplina. Esses materiais, muitas vezes, simples, como apontado por E, podem ser usados para elaborar materiais manipuláveis importantes para a aprendizagem dos conceitos e conteúdos matemáticos, como o ábaco, por exemplo.

Chama a atenção também a novidade do trabalho com as histórias infantis, indicada pelos estudantes da Pedagogia:

LY - Foi muito importante a atividade com o livro de literatura infantil com o conteúdo matemático, ainda não havia pensado na possibilidade de ensinar matemática com livros de história infantil. (NII - 2015/2016)

LG - O manuseio dos materiais didáticos, bem como a discussão de novos meios de utilizá-los me chamou a atenção, pois em toda minha vida escolar o único material que utilizei foi o material dourado, sempre da mesma forma. Além disso, a questão dos livros infantis com conteúdos matemáticos foi muito importante, pois o uso dos livros nunca ocorreu de forma tão lúdica para um público infantil, como foi na disciplina de matemática I (NII - 2017/2018)

As histórias infantis passam a ser vistas como uma estratégia possível para um ensino de matemática mais contextualizado, divertido e significativo. Uma prática que não foi vivenciada/evidenciada nas memórias da Educação Básica, mas no curso de formação inicial, passa a ser alternativa para um processo interdisciplinar, que vai além dos conceitos matemáticos.

Para Lopes (2009, p. 66):

A leitura de textos que tenham como objeto conceitos e procedimentos matemáticos, história da matemática ou reflexões sobre a matemática, seus problemas, seus métodos, seus desafios pode, porém, muito mais do que orientar a execução de determinada técnica, agregar elementos que não só favoreçam a constituição de significados dos conteúdos matemáti- 
cos mas também colaborem para a produção de sentidos da própria matemática e de sua aprendizagem pelo aluno.

Assim é possível sair dos exercícios de repetição e da tabuada para dar sentido e significado ao que se aprende e ao que se ensina. A potencialidade das histórias infantis é descoberta para a dinamicidade das aulas, além de permitir a integração entre a alfabetização matemática e linguística.

\section{O professor de matemática da Educação Básica}

Em sua maioria, os relatos remetem à figura do professor, tornando-o inesquecivel, em uma perspectiva positiva ou negativa:

M-Quando conheci o professor Marcel, que me acompanhou da 5a serie até o 3o ano do ensino médio, minha vida se complicou, excelente professor, porém muito exigente, pelo meu semblante ele sabia que eu não havia entendido nada da matéria. (NI - 2015/2016)

L - Percebi que a matemática pode ser uma matéria gostosa de dar e de aprender, depende muito da formação do professor e como ele pretende dar as matérias, é importante o professor gostar do que faz. (NII - 2015/2016)

$T$ - A Dona Rô sempre me instigava a conhecer matemática, pois antes de apresentar o conteúdo ela nos dava problemas para buscarmos formas de resolve-los. (NI-2015/2016)

LI - Uma situação que eu tenho positivamente foi quando uma professora do 8o ano montou uma musiquinha que continha as combinações dos sinais e como agir em operações de potência. Foi essa mesma professora que marcou a minha vida, porque ela nunca desistiu de mim, me colocava sempre para cima e nunca deixava desistir e sempre me ajudava e ensinava quando não entendia. (NII - 2016/2017)

$L G$ - [...] ela me marcou muito, pois era divertida e deixava a turma à vontade para fazer perguntas e conversar sobre outros assuntos além da disciplina de Matemática. Essa professora suge- riu a leitura do livro "O homem que calculava", que me marcou muito, pois lia escondido em outras aulas, e em algumas situações soltava uma gargalhada na sala de aula e dava a desculpa que me lembrei de uma piada, para disfarçar. (NI-2017/2018)

O desenvolvimento profissional do professor começa antes mesmo da entrada no curso de formação inicial, quando tem início sua experiência como aluno, e nos exemplos de professores que teve (GARCíA, 1992). Há uma tendência a repetir, na docência, as práticas que vivenciou enquanto aluno. No entanto, quando é possivel tomar consciência dessas práticas, por meio das suas próprias narrativa e da narrativa dos colegas, refletindo sobre elas e vivenciando outras alternativas, o cenário pode ser modificado como aponta a estudante LG:

LG - Por fim, de todas as comparações, diferenças e aprendizados entre minha vida escolar e a disciplina de matemática cursada ano passado, foi possivel me aprimorar como professora, não repetir os mesmos erros que ocorreram em minha vida escolar, e sempre lembrar que não existe apenas uma forma de ensinar, nem de aprender, por isso a importância de mostrar todas as formas aos meus futuros alunos, sempre inovando. (NII - 2017/2018)

As concepções do ser docente encontramse enraizadas nos contextos e histórias individuais que antecedem até mesmo a entrada na escola. Constrói-se um papel para o professor, em que há traços comuns, por exemplo, nas brincadeiras infantis. Ao brincar de escolinha, sempre há um quadro negro, cadernos, papéis para escrever, recreio, merenda, o professor falando (em tom autoritário) e os alunos ouvindo (sem muito questionar). As representações construídas remetem a uma prática socialmente difundida e encontrada em muitas memórias.

As características que tornam marcantes os professores são variadas, destacando aspectos profissionais e pessoais, tanto em seu 
caráter positivo quanto negativo. Positivamente, são lembrados os professores que respeitavam o aluno, utilizavam recursos manipuláveis para o ensino de matemática, pois auxiliavam no conteúdo - como o caso da Dona Rô com o bolo para ensinar frações. O professor que usava músicas e desenhos é lembrado e indicado como um elemento motivador da escolha da profissão (professora de matemática).

As narrativas evidenciam que a docência não se esgota na dimensão técnica, mas está diretamente relacionada com a dimensão pessoal, na relação aluno-professor, seja de afeto, seja de indiferença, seja de desrespeito.

Negativamente, a figura do professor é lembrada pelo caráter pouco democrático e punitivo, em momentos de avaliação, de práticas nada motivadoras como apontam B e MA:

B - As tarefas eram bastante repetitivas e longas. Listas de arme e efetue, problemas e "continhas" sem fim só me faziam ter vontade de ir embora daquela aula. As avaliações eram apenas para saber se o aluno tinha decorado o que o professor disse em sala de aula. (NI2015/2016)

MA - Recordo-me também de ter vergonha e ser reprimida pelos professores por fazer contas de multiplicação com os dedos. [...] Os jogos que eram levados pela professora eram fichas que continham uma divisão ou multiplicação que você deveria escolher uma e resolver na frente de toda a turma. Se você respondesse errado o seu grupo perdia pontos. Era constrangedor. (NI - 2015/2016)

Situações são narradas pelos estudantes, destacando as duas experiências, assim comparam professores marcantes, tanto pelo aspecto positivo quanto negativo, como nos aponta a aluna JX:

$J X$ - Me lembro de uma situação no ensino médio, no primeiro ano que o professor tampou um giz na minha testa por ter virado para pedir um lápis e isso me fez pegar mais repulsa contra a matéria, pois não gostava dele. E no segun- do e terceiro ano do ensino médio também um professor me marcou, só que positivamente por ter me feito gostar e compreender novamente a matemática. (NI-2016/2017)

Após cursarem a disciplina, os futuros professores propõem-se a uma prática mais significativa, com o uso de jogos e brincadeiras, e materiais como o ábaco, o Tangram, a torre de Hanói, na resolução de problemas, para favorecer uma matemática mais próxima do aluno, o que constrói um objetivo para essa formação, que "não se constrói por acumulação (de cursos, conhecimento ou técnicas) mas, sim através de reflexibilidade crítica sobre as práticas e de reconstrução permanente de uma identidade pessoal" (NÓVOA, 1992, p. 25).

Essa identidade se constrói na história de vida, no grupo de formação, em que é possivel narrar e refletir sobre lembranças escolares, enquanto discentes, e nos estudos teóricos e práticos, na formação inicial. Nessa construção, o estudante de Pedagogia é convidado a debruçar-se sobre si mesmo, sobre sua experiência com a matemática, e lhe é oferecida a possibilidade de evidenciar seu aprendizado, reintegrando e aprofundando conhecimentos. $M$ aponta que procurou uma área profissional que não tivesse a matemática devido a sua experiência anterior, porém, ao reencontrá-la na faculdade, pôde dar novos sentidos a essa disciplina.

M - Tanto fiz para buscar um curso que passaria longe dessa matéria (matemática) e acabei me reencontrando com a mesma na faculdade. [...] No decorrer do período pude ver que a matemática não é nenhum logaritmo insolúvel, nós como futuros professores podemos mudar a maneira como a matéria é vista. (NII - 2015/2016)

Catalisar experiências vividas no ambiente escolar para a formação de professores abre espaço para a reflexão, para a crítica, para a revisão de conceitos e a construção de outros olhares. 


\section{Algumas considerações}

Buscamos, neste artigo, investigar as percepções de estudantes de Pedagogia sobre sua formação matemática na Educação Básica e na disciplina Fundamentos Teóricos e Metodológicos da Matemática I, a partir de narrativas escritas. Selecionamos alguns aspectos para este trabalho, e outros desdobramentos ainda poderão ser feitos, a partir dos dados, inclusive dos "não ditos", pois muitas são as possibilidades com o exercício narrativo, para a constituição dos saberes docentes e do desenvolvimento profissional.

As narrativas fizeram emergir inúmeros dados que evidenciam lembranças da matemática, enquanto estudantes, como a repetição e a reprodução de procedimentos e algoritmos, para que acontecesse a aprendizagem, explicitando uma matemática sem sentido, em que o professor se pautava quase que exclusivamente no livro didático e na exposição dos conteúdos. Contudo, alguns estudantes de Pedagogia relatam que tiveram, em sua escolarização, um contato com outras maneiras de ensinar os conceitos matemáticos, como a ida ao supermercado, o bolo para abordar frações, músicas e outros recursos, como o material dourado e o ábaco.

Essas situações foram problematizadas durante a disciplina de Fundamentos Teóricos e Metodológicos da Matemática I e levou a indícios de mudança na forma de ver a matemática que podem influenciar a futura prática profissional dos professores. Nesse sentido, Nacarato (2010) aponta a necessidade da formação romper com crenças e culturas de aula de matemática que foram vivenciadas na Educação Básica.

Os estudantes também explicitaram a importância dos estudos teóricos, para o desenvolvimento desse novo olhar, além das problematizações e das atividades práticas durante a FTM I, que auxiliaram na (re)construção de como percebiam o ensino de matemática.
As narrativas revelaram marcas positivas e negativas referentes aos professores da Educação Básica que foram lembrados, ora por respeitaram e valorizarem os alunos, ora por aprofundarem sentimentos de medo e angústia em relação à disciplina. Assim, eles tomaram consciência de como a matemática foi marcante, de alguma forma, em suas vidas, percebendo que podem ser professores que mostrem a seus alunos que não precisa haver uma relação de sofrimento na aprendizagem dos conceitos e dos conteúdos matemáticos.

Além disso, podemos perceber que as narrativas são carregadas de saberes existenciais (TARDIF, 2012), pois são apresentados aspectos afetivos, pessoais e de suas histórias de vida.

Por fim, lembramos que as disciplinas dos cursos de formação inicial, de modo geral, apresentam carga horária reduzida, pela própria característica do curso, que busca formar um professor polivalente, responsável pelas diferentes áreas do conhecimento. Podemos pensar este processo formativo como um início do saber-fazer docente, em que o professor dos anos iniciais não precisa saber tudo o que irá ensinar, pois compreendemos que um dos papéis do formador é mostrar possibilidades e promover experiências que os estudantes poderão colocar em prática, em sala de aula, além de fomentar a necessidade de uma contínua formação diante dos desafios da profissão.

\section{Referências}

BARDIN, Laurence. Análise do conteúdo. Lisboa: Edições 70, 1977.

BOGDAN, Robert C.; BIKLEN, Sari K. Investigação qualitativa em educação: uma introdução à teoria $e$ aos métodos. Porto: Porto Editora, 1994.

BOLIVAR, Antonio. A pesquisa biográfica e narrativa: fundamentos epistemológicos e metodológicos. [201-]. Disponível em: <http://www.ugr.es/ aboli- 
var/Publicaciones.html>. Acesso em: 05 mar. 2015.

CUNHA, Maria I. Conta-me agora! As narrativas como alternativas na pesquisa e no ensino. Revista da Faculdade de Educação, São Paulo, v. 23, n. 1-2, 1997. Disponível em: <http://www.scielo.br/scielo. php?script=sci_arttext $\&$ pid=S0102255519970001000 10\#1aut>. Acesso em: 20 mai. 2008.

FIORENTINI, Dario. Alguns modos de ver e conceber o ensino da matemática no Brasil. Zetetiké, Campinas, SP, v. 3, n. 4, p. 1-37, 1995.

GARCÍA, Carlos M. A formação de professores: novas perspectivas baseadas na investigação sobre o pensamento do professor. In: NÓVOA, António. (Org.). Os professores e sua formação. Lisboa: Dom Quixote, 1992. p. 51-76.

HAMMERNESS, Karen, DARLING-HAMMOND, Linda, BRANSFORD, John, BERLINER, David, COCHRAN-SMITH, Marilyn, MACDONALD, Morva, ZEICHNER, Kenneth. How teachers learn and develop. In: DARLING -HAMMOND, Linda; BRANSFORD, John. (Eds.). Preparing teachers for a changing world: what teachers should learn and be able to do. United States of America: Jossey-Bass, 2005. p. 358-389.

JOSSO, Marie-Christine. Da formação do sujeito... Ao sujeito da formação. In: NÓVOA, António; FINGER, Matthias. (Orgs.). 0 método (auto)biográfico e a formação. Natal: EDUFRN, 2010. p. 59-79.

LOPES, Celi A. E. Escritas e leituras na educação matemática. Belo Horizonte: Autêntica, 2009.

MARCELO, Carlos; VAILLANT, Denise. Desarrollo profesional docente: ¿Cómo se aprende a enseñar? Madri: Narcea, 2009.

MORALES, Pedro. A relação professor-aluno: o que é, como se faz. São Paulo: Edições Loyola, 1999.

NACARATO, Adair M. A formação matemática das professoras das séries iniciais: a escrita de si como prática de formação. Bolema, Rio Claro, SP, v. 23, n. 37, p. 905-930, 2010.

NACARATO, Adair M.; MENGALI, Brenda L. S.; PASSOS,
Cármen L. B. A matemática nos anos iniciais do Ensino Fundamental: tecendo fios do ensinar e do aprender. Belo Horizonte: Autêntica, 2009.

NÓVOA, Antônio. Os professores e a sua formação. Lisboa: Dom Quixote, 1992.

PASSOS, Cármen L. B. Trajetória de uma professora que ensina matemática nos anos iniciais marcada em narrativas. In: FURLANETTO, Ecleide C.; NACARATO, Adair N.; GONÇALVES, Terezinha V. O. Espaços formativos, trajetórias de vida e narrativas docentes. Curitiba: CRV, 2018. p. 181-193.

PLACCO, Vera M. N. S.; SOUZA, Vera L. T. Aprendizagem do adulto professor. São Paulo: Loyola, 2006.

SERODIO, Liana A.; PRADO, Guilherme V. T. Metodologia narrativa de pesquisa em Educação na perspectiva do gênero discursivo bakhtiniano. In: PRADO, Guilherme V. T.; SERODIO, Liana A.; PROENÇA, Heloisa D. M.; RODRIGUES, N. C. Metodologia narrativa de pesquisa em Educação: uma perspectiva bakhtiniana. São Carlos: Pedro \& João Editores, 2015. p. 91-127.

SERRAZINA, Maria L. Conhecimento matemático para ensinar: papel da planificação e da reflexão na formação de professores. Revista Eletrônica de Educação, São Carlos, SP, v. 6, n. 1, p. 266-283, mai. 2012.

SERRAZINA, Maria L., MATOS, José M. Didáctica da matemática. Lisboa: Universidade Aberta, 1996.

TARDIF, Maurice. Saberes docentes e formação profissional. São Paulo: Vozes, 2012.

VIÑAO FRAGO, Antonio. Por una historia de la cultura escolar: enfoques, cuestiones, fuentes. In: CONGRESO DE LA ASOCIACIÓN DE HISTORIA CONTEMPORÁNEA, 3., 1998, Valladolid - España. Anais... Valladolid - España, 1998, p. 167-183. Disponivel em: <http:// www.ahistcon.org/docs/Valladolid.pdf>. Acesso em: 11 ago. 2012.

Recebido em: 10.01.2019 Aprovado em: 30.03.2019 
Jane Maria Braga é doutoranda em Educação pela Universidade Federal de Juiz de Fora - UFJF - e mestre em Educação. Formada em Pedagogia também pela UFJF. Professora e Coordenadora Pedagógica da rede municipal de ensino de Juiz de Fora. Membro do Grupo de Estudos e Pesquisas em Educação Matemática - GREPEM. e-mail: janebraga.jf@gmail.com

Secretaria de Educação de Juiz de Fora. Av. Getúlio Vargas, 200 - Centro. Juiz de Fora, MG. CEP: 36010-909. Telefone: (32) 3690-7341

Reginaldo Fernando Carneiro é Doutor em Educação, pela Universidade Federal de São Carlos - UFSCar. Professor da Faculdade de Educação, do Programa de Pós-Graduação em Educação e do Programa de Pós-Graduação em Educação Matemática da Universidade Federal de Juiz de Fora - UFJF. Coordenador do Grupo de Estudos e Pesquisas em Educação Matemática - GREPEM. e-mail: reginaldo.carneiro@ufjf.edu.br

Universidade Federal de Juiz de Fora. Faculdade de Educação. Rua José Lourenço Kelmer, s/n - Campus Universitário, São Pedro, Juiz de Fora, MG. CEP: 36036-900. Telefone: (32) 2102-3650 